\title{
Thromboembolism in inflammatory bowel diseases: a report from Saudi Arabia
}

This article was published in the following Dove Press journal:

Clinical and Experimental Gastroenterology

I February 201 |

Number of times this article has been viewed

\author{
Hussain Issa' \\ Sami Al-Momen' \\ Bahaa Bseiso' \\ Ghada Ali Al-Janobi' \\ Mohammed A Aljama' \\ Fadel Ali Almousa' \\ Mahdi E Al-Jarodi' \\ Ahmed H Al-Salem ${ }^{2}$ \\ 'Department of Internal Medicine, \\ King Fahad Specialist Hospital, \\ Dammam, Saudi Arabia; ${ }^{2}$ Department \\ of Pediatric Surgery, Maternity and \\ Children Hospital, Dammam, Saudi \\ Arabia
}

Correspondence: Ahmed H Al-Salem PO Box 61015, Qatif 31911, Saudi Arabia

Mobile +00966505818009

Email ahsalsalem@hotmail.com

\begin{abstract}
Thromboembolism (TE) is a serious but under-recognized complication of inflammatory bowel disease (IBD). This is specially so in developing countries where the incidence of IBD is low. In Saudi Arabia, IBD is considered to be rare, but the incidence is increasing. Where the clinical manifestations resemble those of developed countries, TE as a complication of IBD is considered to be very rare. This report describes six IBD patients with TE. This importance of the complication of TE is stressed, and physicians caring for these patients should be aware of it in order to obviate potential morbidity and mortality.
\end{abstract}

Keywords: thromboembolism, inflammatory bowel disease, Crohn's disease, ulcerative colitis

\section{Introduction}

Thromboembolism (TE) is now a well-recognized complication of inflammatory bowel disease (IBD) to the extent that it is considered an extraintestinal manifestation of IBD. ${ }^{1,2}$ The reported frequency of TE in IBD varies widely in the literature, but patients with ulcerative colitis (UC) and Crohn's disease (CD) have a three-fold risk of developing TE when compared with the general population. ${ }^{3,4} \mathrm{TE}$ represents a significant cause of morbidity and mortality, and among IBD patients mortality following an acute TE ranges from $8 \%$ to $25 \% .{ }^{1,5}$ One factor contributing to this is the fact that the diagnosis of TE in these patients is either overlooked or delayed, as these patients are usually unwell and on several medications, and new symptoms are usually attributed to their disease or to the side effects of their medications. TE in IBD appears to be disease specific, and although there seems to be an equal risk of developing TE in $\mathrm{UC}$ and $\mathrm{CD}$, there are reports suggesting that $\mathrm{UC}$ patients are at a greater risk for TE when compared with CD patients. ${ }^{4,6}$ In Saudi Arabia, IBD is considered to be rare, but there is a definite and appreciable increase in the incidence of IBD..$^{7-9}$ The manifestations of IBD in Saudis are reported to be similar to those of developed countries, but in none of the published series so far was there a report of TE as a complication of IBD. ${ }^{7-9}$ There were two case reports, however: an aortic thrombosis complicating $\mathrm{CD}$ disease ${ }^{10}$ and a cerebral venous thrombosis as a complication of UC. ${ }^{11}$ This report describes our experience with TE in six patients with IBD complicated by pulmonary embolism in four of them. The prevalence of TE complications in IBD in Saudi Arabia is not known, and this report should stimulate further national studies to determine this. 


\section{Case reports}

\section{Case no. I}

A 23-year-old, nonsmoking, Saudi male was referred to our hospital complaining of abdominal pain for 18 months. He was well until 14 months prior to presentation, when he started to complain of intermittent colicky, mostly rightsided abdominal pain, not related to meals and associated with occasional nausea, vomiting, and frequent bowel motion up to six or seven times daily but without blood or mucous. Four months after developing the pain, his appetite decreased and he lost $30 \mathrm{~kg}$ in weight. His family history was unremarkable except for a history of CD in third-degree relatives. On examination he was found to be thin built and not in distress, and his vital signs were normal. His abdomen was mildly tender in the right upper quadrant with no palpable masses or organomegaly. Laboratory investigations showed the following: white blood cell count (WBC) $5.34 \times 10^{9} / \mathrm{L}$, hemoglobin $(\mathrm{Hb}) 7.4 \mathrm{~g} / \mathrm{dL}$, hematocrit $24.7 \%$, platelets $701 \times 10^{9} / \mathrm{L}$, erythrocyte sedimentation rate (ESR) $75 \mathrm{~mm} / \mathrm{h}$, total bilirubin $1.5 \mathrm{umol} / \mathrm{L}$, alkaline phosphatase 100 unit/L, alanine aminotransferase 25 unit/L, aspartate aminotransferase 24 unit/L, $\gamma$-glutamyl transpeptidase 16 unit/L, total protein $56 \mathrm{~g} / \mathrm{L}$, albumin $15 \mathrm{~g} / \mathrm{L}$, phosphorus $1.29 \mathrm{mmol} / \mathrm{L}$, calcium $1.93 \mathrm{mmol} / \mathrm{L}$, antithrombin III $90.1 \mathrm{sec}$ (normal 75-125), activated protein C resistance 88 (normal 70-140), and protein S 54.8 L (normal 50-120). Lower gastrointestinal endoscopy showed ileitis with nodular terminal ileal mucosa and aphthous ulcers with normal colon. Multiple biopsies were taken and the histopathology revealed $\mathrm{CD}$. Computed tomography (CT) enterography showed segmental wall thickening of the ileal loops with creeping fat and enlarged mesenteric lymph nodes most likely representing $\mathrm{CD}$ as well as partial obstruction at the distal ileum with significant dilated proximal bowel loops. There was also inferior vena cava thrombosis with central intraluminal filling defect extending to the right internal iliac vein (Figures 1 and 2). Pulmonary CT revealed small subsegmental pulmonary emboli. This was treated with low-molecular-weight heparin. There was no family history of TE. He was started on Pentasa, gradually increasing the dose until it reached $1 \mathrm{~g}$ three times daily + Caltrate, iron, and vitamin D supplements. Azathioprine was introduced with a dose of $50 \mathrm{mg}$ once daily. He quickly responded to treatment and his laboratory follow-up showed a rise in his hemoglobin level reaching $10 \mathrm{~g} / \mathrm{dL}$, normalization of his calcium level, and elevation of his albumin level reaching $28 \mathrm{~g} / \mathrm{L}$. His inflammatory markers, including ESR and CRP, gradually came down.

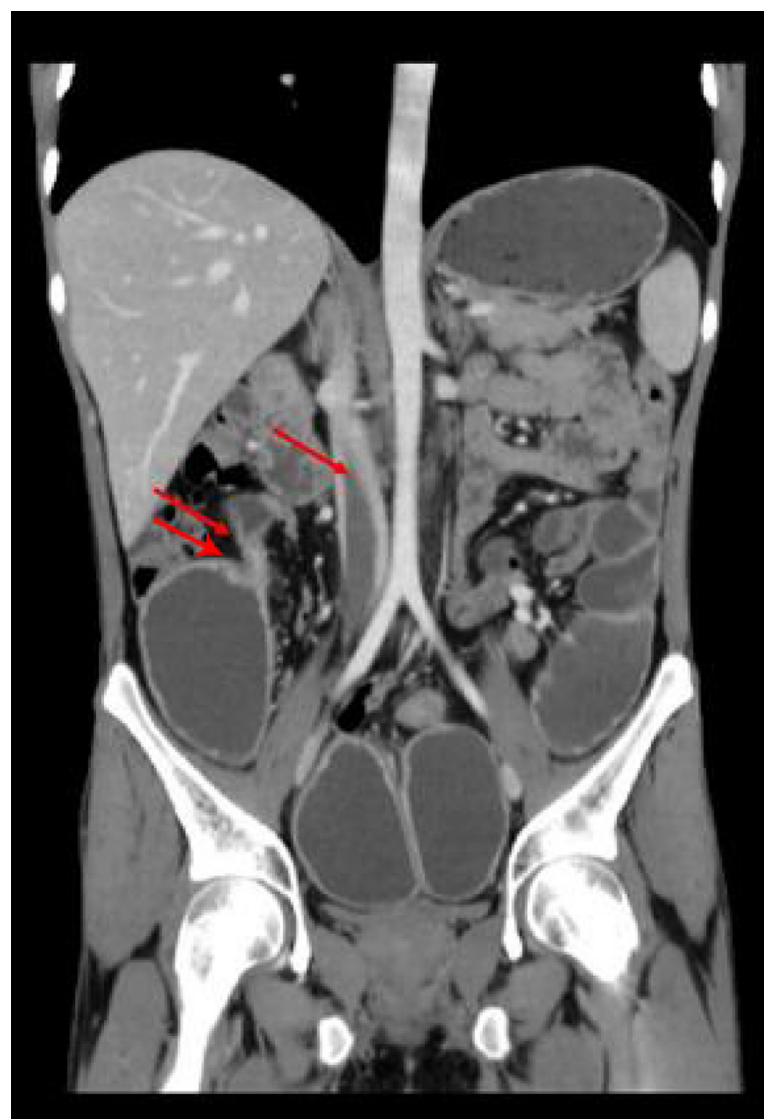

Figure I CT scan of the abdomen showing inferior vena cava thrombosis (single arrow). Note also partial obstruction at the distal ileum with significant dilated proximal bowel loops and bowel thickening (double arrow).

\section{Case no. 2}

A 39-year-old, nonsmoking, Saudi male with a known case of $\mathrm{CD}$ was diagnosed 5 years previously in a local hospital. He was started on azathioprine, prednisolone, and mesalazine, but he was not compliant to treatment. Two years later,

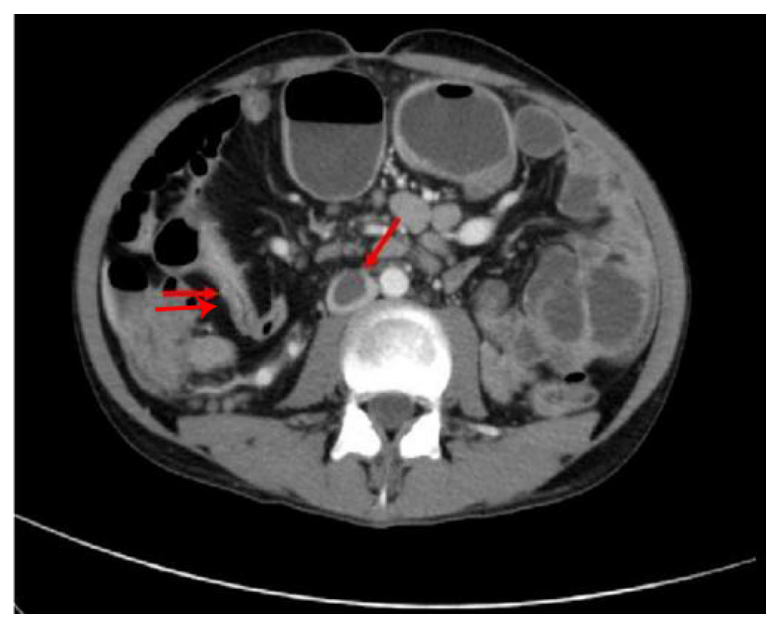

Figure 2 Abdominal CT scan showing inferior vena cava thrombosis (single arrow) with dilated and thickened small bowel loops (double arrow). 
he developed enterovesical fistula and was started on antitumor necrosis factor (TNF) (infliximab). He received four cycles with partial improvement and then was lost for follow-up. He presented to our hospital with a 20-day history of abdominal pain, distention, and fever with chills. He presented a history of intermittent fecaluria and pneumaturia for the last few months with a history of decreased appetite and weight loss of about $10 \mathrm{~kg}$. During examination, his abdomen was distended with ascites and decreased bowel sounds. He underwent a CT scan, which revealed an enterocolic fistula, superior mesenteric vein thrombosis, and a few enlarged retroperitoneal and mesenteric lymph nodes (Figure 3). He was scheduled for surgery and underwent ileocecal resection, sigmoid colectomy, terminal ileostomy, and colostomy. Pathology of the resected intestines showed changes consistent with CD with ulcerations, fissuring, and fistula formation. He did not receive thromboprophylaxis postsurgery. He was stable until the 12th postoperative day when he suddenly developed shortness of breath and was found to be tachypneic, tachycardic, and hypotensive. Spiral CT of the chest showed evidence of a small left upper lobe subsegmental pulmonary embolism (Figure 4). There was no family history of TE. He was started on low-molecular-weight heparin, and his workup showed a low level of antithrombin III and factor V Leiden, suggestive of underlying thrombophilia, so he was started on warfarin with a stable hospital course and restarted on anti-TNF (infliximab). Currently, he is being followed up in the clinic, is doing well, and is waiting for closure of his stomas.

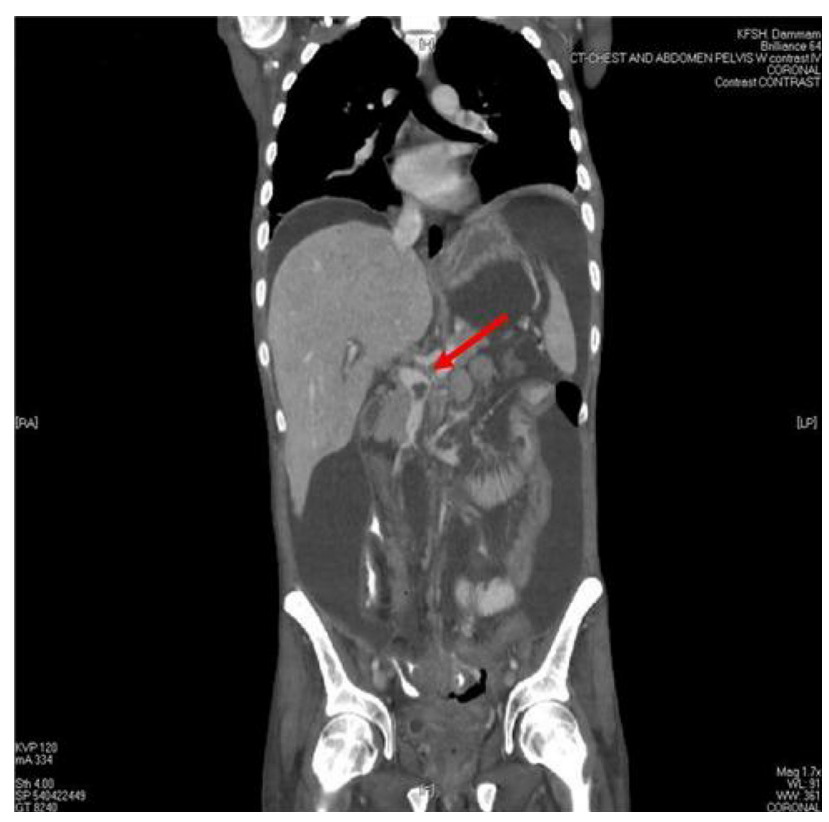

Figure 3 CT scan of the abdomen showing thrombosis in the superior mesenteric vein (arrow). Also note the ascites.

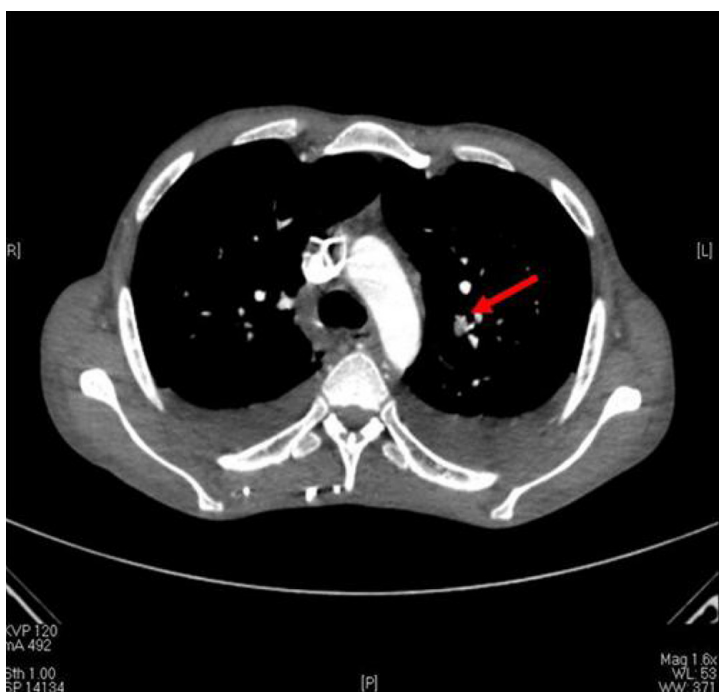

Figure 4 CT scan of the chest showing pulmonary embolism (arrow).

\section{Case no. 3}

A 49-year-old, Saudi female was diagnosed as having ulcerative pancolitis and was referred to our hospital for further management. She was managed with mesalazine and prednisolone. Her disease was nonremitting. She developed left cerebrovascular accident. A Doppler ultrasound showed total occlusion of the left carotid artery and a 2-D transesophageal echo showed a normal heart with no intramural thrombus. She was not on thromboprophylaxis. During her stay at our hospital she also developed right popliteal deep venous thrombosis and pulmonary embolism. She was started on low-molecular-weight heparin but continued to have hematochezia and a drop in her hemoglobin, so it was decided that an inferior vena cava filter should be inserted. A repeat colonoscopy showed moderately severe pancolitis with multiple pseudo polyps. Histopathology was compatible with UC with no dysplasia or cytomegalovirus. Her investigations showed the following: $\mathrm{Hb} 3.8 \mathrm{~g} / \mathrm{dL}$, mean corpuscular volume 61.5 , mean corpuscular hemoglobin 17.6 , platelets $432,000 / \mathrm{mm}^{3}$, ESR 75, and albumin $27 \mathrm{~g} / \mathrm{L}$. Her liver function tests and renal profile were normal. All studies for thrombophilia were negative, including protein $\mathrm{S}$, protein $\mathrm{C}$, antithrombin III, and factor $\mathrm{V}$ Leiden. Lupus anticoagulant was negative and JAK2 mutation was ordered. She was started on prednisolone and azathioprine and was titrated up to $100 \mathrm{mg}$ once daily in addition to aspirin $100 \mathrm{mg}$ once daily. She went into remission after that and steroids were discontinued. She was maintained on mesalazine $1 \mathrm{~g}$ twice daily and azathioprine $100 \mathrm{mg}$ orally once daily.

\section{Case no. 4}

A 17-year-old female presented to our hospital with easy fatigability, palpitation, dizziness, and pallor, and decreased 
appetite for 1 month. This was associated with mild abdominal pain and bleeding from the rectum. She was intentionally trying to lose weight and over a 3-month period she lost about $20 \mathrm{~kg}$. Clinically, she was pale but not jaundiced and was not in respiratory distress. Her chest and abdominal examinations were normal. Her investigations showed the following: WBC $3.4 \times 10^{9} / \mathrm{L}, \mathrm{Hb} 3.1 \mathrm{~g} / \mathrm{dL}$, platelets $106,000 / \mathrm{mm}^{3}$, calcium $8.2 \mathrm{mmol} / \mathrm{L}$, albumin $3.4 \mathrm{~g} / \mathrm{L}$, and total bilirubin $1.55 \mathrm{umol} / \mathrm{L}$. All other investigations were normal. She received a blood transfusion and underwent a colonoscopy. The colonoscopy showed markedly congested, erythematous mucosa of the left colon, which was oozing fresh blood with diffuse ulceration, granularity, and submucosal hemorrhage. Her upper endoscopy showed chronic gastroduodenitis. She was diagnosed as having UC of the left colon and was started on treatment with prednisolone, mesalamine, omeprazole, steroid enema, and mesalazine enema. She was discharged home in a good general condition but readmitted 2 months later with bilateral lower limb edema of 1-week duration. This was associated with pain on walking. Examination showed the following: prothrombin time $(\mathrm{PT}) 14.6 \mathrm{sec}$ (control = $13.4 \mathrm{sec}$ ) and partial thromboplastin time (PTT) $35 \mathrm{sec}$ (control = $30.2 \mathrm{sec}$ ); antithrombin III was slightly reduced, but protein $\mathrm{C}$, protein $\mathrm{S}$, plasminogen, and factor $\mathrm{V}$ Leiden were all within normal limits. Lupus anticoagulation, antinuclear antibodies (ANA), and anti-DNA were negative. Repeated factor III was normal; ANA, antimitochondrial antibodies, antiribosomal antibodies, antibasement membrane antibodies, and antineutrophil (ANCA) antibodies were all negative. Her $\mathrm{Hb}$ was $9 \mathrm{~g} / \mathrm{dL}$, WBC $5.7 \times 10^{9} / \mathrm{L}$, and platelets $223,000 / \mathrm{mm}^{3}$. She was diagnosed as having bilateral deep vein thrombosis. She was not using oral contraceptive pills, and there was no family history of TE. While in hospital she developed chest pain associated with shortness of breath. Pulmonary angiography showed evidence of pulmonary embolism with a filling defect and a thrombus was seen within the right inferior pulmonary artery. She was started on anticoagulant therapy and was discharged 2 weeks later with an international normalized ratio of 3.3. She was subsequently followed up in clinic and was well.

\section{Case no. 5}

A 50-year-old, Saudi female presented to the emergency department with a 2-month history of bloody diarrhea and lower abdominal pain. Clinically, she was found to be pale with stable vital signs and a mild generalized abdominal tenderness. Initial investigations showed the following: WBC $9.4 \times 10^{9} / \mathrm{L}$, $\mathrm{Hb} 8 \mathrm{~g} / \mathrm{dL}$, ESR 79, and albumin $2.6 \mathrm{~g} / \mathrm{dL}$. Her liver and renal function tests were normal. Flexible sigmoidoscopy up to the distal transverse colon revealed uniform involvement with moderately severe colitis. Histopathology was compatible with UC. She was started on mesalazine tablets in addition to prednisolone $40 \mathrm{mg}$ daily. She was discharged to be followed up in the clinic. During prednisolone tapering she relapsed after 5 weeks. She presented to us again unwell with severe abdominal pain, vomiting, and fever. Clinically, she was found to have severe abdominal tenderness, guarding, and positive rebound tenderness. Her investigations showed the following: WBC $3.1 \times 10^{9} / \mathrm{L}, \mathrm{Hb} 10.1 \mathrm{~g} / \mathrm{dL}$, PLT $152,000 / \mathrm{mm}^{3}$, INR 1.2 , PTT 44, total bilirubin $2.13 \mathrm{umol} / \mathrm{dL}$, direct bilirubin $2 \mathrm{umol} /$ $\mathrm{dL}$, and alkaline phosphatase $41 \mathrm{IU} / \mathrm{L}$. Abdomen X-rays showed air under the diaphragm. She was admitted to the intensive care unit (ICU), was resuscitated, and underwent an emergency laparotomy. There was purulent fluid in the peritoneal cavity and a perforation at splenic flexure. Peritoneal lavage and subtotal colectomy were carried out, leaving the cecum and $10 \mathrm{~cm}$ from proximal ascending colon, which was brought out as a colostomy. The rectal stump was left behind. Her postoperative course was complicated by wound infection, which was treated with antibiotics, and intrahepatic cholestasis related to total parenteral nutrition, which resolved gradually. She was maintained on mesalazine, as she had residual colon left behind. During her stay in the ICU she developed weakness in all her limbs and was difficult to be extubated. Neurological examination revealed high mental function with intact cranial nerves but weakness in all limbs $2 / 5$ with absent reflexes. Electromyography and nerve conduction studies revealed motor polyneuropathy that was more pronounced in the lower limbs, compatible with critical illness polyneuropathy. Her electrolytes, calcium, phosphorus, magnesium, trace elements, and vitamins were corrected and optimized. Physical therapy was intensified and, because of her prolonged stay in ICU, unfractionated subcutaneous heparin 5000 IU subcutaneously was given every $8 \mathrm{~h}$. She had tracheostomy, but it was closed after improvement in her strength. The muscle strength in her limbs improved gradually, reaching $3 / 5$ over 8 weeks after the operation, when she was found to have swelling and discoloration in her left lower limb. A Doppler ultrasound confirmed the presence of deep venous thrombosis in the left popliteal and femoral veins. Thrombophilia screening showed the following: protein S and C, antithrombin III, lupus anticoagulation, ANA, and anti-DNA were all negative. She was fully anticoagulated initially with heparin and subsequently with warfarin. Warfarin was continued for 6 months. She was maintained during this period on mesalazine tablets, in addition to suppositories. Proctoscopy and endoscopy through stoma revealed evidence of colitis. She underwent resection of 
remaining colon (rectum, proximal ascending colon) and had ileoanal pouch anastomosis. During follow-up over 5 years, no recurrence of thrombosis was observed.

\section{Case no. 6}

A 17-year-old, Saudi female was diagnosed as UC 9 months prior to her presentation to our hospital. Colonoscopy revealed pancolitis. She was maintained on mesalazine $1000 \mathrm{mg}$ three times daily but was not compliant with her medication. She was admitted with moderate exacerbation of UC and severe iron deficiency anemia. Her investigations showed the following: WBC $6.7 \times 10^{9} / \mathrm{L}, \mathrm{Hb} 5.3 \mathrm{~g} / \mathrm{dL}$, ESR 60, and albumin $2 \mathrm{~g} / \mathrm{dL}$. Her liver and renal function tests were normal. She received a blood transfusion and was started on prednisone $40 \mathrm{mg}$ once daily and iron tablets. During her hospital stay she developed left leg swelling and calf pain. A Doppler ultrasound of the left lower limb revealed complete obstruction of the upper half of the femoral vein and popliteal vein by a thrombus. Thrombophilia study, including protein $\mathrm{S}$ and $\mathrm{C}$, antithrombin III, and plasminogen functional chromogenic assay, was normal. Lupus anticoagulant and ANA were negative. She was started on unfractionated heparin to maintain her PTT at twice the normal limit and subsequently was put on warfarin $5 \mathrm{mg}$ daily. She tolerated the treatment well but was readmitted with hematochezia 2 weeks after her discharge. Her INR was 1.8. As heparin was reported to have an anti-inflammatory effect in patients with UC, warfarin was held. It was decided to keep her on subcutaneous unfractionated heparin at a dose of 7500 IU subcutaneously twice daily. She was kept on subcutaneous heparin for 6 months, and the signs of DVT disappeared. No recurrence of DVT was noticed during her follow-up over 10 years.

\section{Discussion}

IBDs are common in developed countries and are considered to be rare in developing countries. This is specially so for CD, which was described in 1932 and can affect any part of the gastrointestinal tract. ${ }^{12}$ It is common in developed countries, and the incidence is increasing worldwide. For many years, IBD in general and CD in particular were considered very rare or nonexistent in Saudi Arabia. ${ }^{7-9}$ In 1982, the first two cases of CD were reported from Saudi Arabia. ${ }^{13}$ Since then, several reports were published from Saudi Arabia but in all the number of CD patients was small. The largest series reported was from King Faisal Specialist Hospital and Research Center, a tertiary care facility. ${ }^{9}$ They reported 28 patients with $\mathrm{CD}$ seen over a period of 18 years. Subsequently, the number of cases reported increased. A large epidemiological study reported
77 patients with CD seen over a period of 20 years from a large teaching hospital. ${ }^{8}$ This and other studies reported an increase in the incidence of CD in Saudi Arabia. ${ }^{7-9}$ In a previous study over a 20 -year period, the annual incidence of CD increased from 0.32:100,000 in the first 10 years to $1.66: 100,000$ in the subsequent 10 years. ${ }^{8}$ The reason for this increase is not exactly known. One factor is increased awareness of the disease and improved diagnostic criteria. To this add environmental factors and a change in dietary habits. Westernization of dietary habits and exposure to more psychological stresses may have played a role in the increased incidence of CD in Saudi Arabia.

The clinical manifestations of IBD are variable depending on the extent of the disease, but abdominal pain, diarrhea, and weight loss are the main presenting symptoms. One of the rare presentations of IBD that is now being recognized with increasing frequency and considered to be an extraintestinal manifestation is TE. ${ }^{1-3}$ The development of TE is usually associated with probable risk factors such as prolonged immobilization, prior surgery, and the presence of occult neoplasm or an already existing hypercoagulable disorder. IBD is now considered a risk factor for TE, but the reported frequency is variable., ${ }^{3,4}$ Patients with UC or $\mathrm{CD}$ have a three-fold risk of developing TE, but the actual incidence is not known. ${ }^{4}$ It has been reported to range from $1 \%$ to $10 \%$ in clinical studies and from $39 \%$ to $41 \%$ in postmortem studies. ${ }^{2,5,14,15}$ In two large cohort studies, the overall incidence of TE was about $6.5 \%$ in both $\mathrm{UC}$ and CD. ${ }^{4,16}$ This is nearly six-fold higher in autopsies when compared with clinical studies. The reason for this higher incidence of TE in postmortem studies is the fact that a large number of them are silent and may remain so or manifest as a pulmonary embolism like in our patients. In one, TE was discovered incidentally, whereas in four it was complicated by pulmonary embolism. Deep vein thrombosis and pulmonary embolism are the most common types of TE seen in IBD, but there are reports of TE occurring in unusual sites such as cerebral, innominate, retinal, hepatic, and mesenteric veins as well as arterial TE. ${ }^{16,17}$ Our second patient had superior mesenteric vein thrombosis, but our third patient developed left carotid artery thrombosis and right popliteal deep vein thrombosis. The reason for this association of TE and IBD is not exactly known, and several factors have been incriminated. These include the general factors associated with increased risk for TE in general, such as hospitalization, immobilization, and recent surgery. Several other factors have also been proposed to explain the development of TE in IBD, including platelets and coagulation cascade abnormalities as well as factor $\mathrm{V}$ 
Table I Clinical features of six patients with IBD complicated by TE

\begin{tabular}{|c|c|c|c|c|c|c|}
\hline No. & $\begin{array}{l}\text { Age } \\
\text { (years) }\end{array}$ & Sex & Diagnosis & $\begin{array}{l}\text { Extent of } \\
\text { disease }\end{array}$ & Site of thromboembolism & Predisposing factors \\
\hline 1 & 23 & $M$ & $\begin{array}{l}\text { Crohn's } \\
\text { disease }\end{array}$ & Ileum & $\begin{array}{l}\text { Inferior vena cava extending to }(\mathrm{R}) \\
\text { internal iliac vein, pulmonary embolism }\end{array}$ & None \\
\hline 2 & 39 & M & $\begin{array}{l}\text { Crohn's } \\
\text { disease }\end{array}$ & Ileocolic & $\begin{array}{l}\text { Superior mesenteric vein } \\
\text { thrombosis, pulmonary embolism }\end{array}$ & $\begin{array}{l}\text { Surgery, low antithrombin III, and factor V } \\
\text { Leiden, intensive care unit, hospitalization, } \\
\text { immobilization }\end{array}$ \\
\hline 3 & 49 & $\mathrm{~F}$ & $\begin{array}{l}\text { Ulcerative } \\
\text { colitis }\end{array}$ & Pancolitis & $\begin{array}{l}\text { (R) Popliteal vein thrombosis, pulmonary } \\
\text { embolism, (L) carotid artery thrombosis }\end{array}$ & Hospitalization, immobilization \\
\hline 4 & 17 & $\mathrm{~F}$ & $\begin{array}{l}\text { Ulcerative } \\
\text { colitis }\end{array}$ & Left colon & $\begin{array}{l}\text { Bilateral lower limb deep venous } \\
\text { thrombosis, pulmonary embolism }\end{array}$ & None \\
\hline 5 & 50 & $\mathrm{~F}$ & $\begin{array}{l}\text { Ulcerative } \\
\text { colitis }\end{array}$ & Pancolitis & $\begin{array}{l}\text { (L) Femoral and popliteal } \\
\text { vein thrombosis }\end{array}$ & $\begin{array}{l}\text { Surgery, intensive care unit, } \\
\text { hospitalization, and } \\
\text { immobilization }\end{array}$ \\
\hline 6 & 17 & $\mathrm{~F}$ & $\begin{array}{l}\text { Ulcerative } \\
\text { colitis }\end{array}$ & Pancolitis & $\begin{array}{l}\text { (L) Femoral and popliteal } \\
\text { vein thrombosis }\end{array}$ & Hospitalization, immobilization \\
\hline
\end{tabular}

Leiden mutation and hyperhomocysteinemia. ${ }^{1-4}$ This was demonstrated in our second patient, in whom low levels of antithrombin III and factor V Leiden were found (Table 1). The extent of the disease (pancolonic inflammation in UC and colonic involvement in CD) was also shown to correlate positively with the risk of developing TE, but it must be borne in mind that proctocolectomy does not protect from developing TE in these patients. ${ }^{1,17}$ In a review of 98 patients with IBD and TE, it was found that UC patients had extensive colonic involvement and most of the patients with CD had colonic involvement. ${ }^{1}$ Our third patient had severe pancolitis. Another important correlating factor for the development of TE in both $\mathrm{UC}$ and $\mathrm{CD}$ is the disease activity, as $79 \%$ of patients with UC and $80 \%$ of patients with $\mathrm{CD}$ with an intact colon had active disease at the time of TE diagnosis. ${ }^{1}$

Venous TE is a serious complication of IBD that is associated with high morbidity and mortality. ${ }^{1}$ Taking this into consideration, these patients must be followed up closely and investigated for this possibility, because in some of these patients TE may be silent to start with and manifest as pulmonary embolism, which can be fatal. They should also be investigated for the presence of hypercoagulable states including factor V Leiden mutation and hyperhomocysteinemia. In the presence of such conditions, lifelong anticoagulation with warfarin is recommended. ${ }^{1,2,4,5}$ In the presence of contraindication for lifelong anticoagulation, temporary anticoagulation with low-molecular-weight heparin should be considered perioperatively, during hospitalization, and immobilization.

In conclusion, TE is a serious and life-threatening complication of IBD. IBD is relatively rare in Saudi Arabia, but the incidence is increasing. This report describes six patients with IBD complicated by TE and pulmonary embolism. This complication should be borne in mind, and physicians caring for these patients must be aware of this, as early diagnosis is important in order to obviate the risks of subsequent morbidity and mortality. The decision to start anticoagulant therapy in these patients must, however, be weighed against the potential risk of bleeding, and the treatment of TE in these patients needs to be standardized.

\section{Disclosure}

The authors report no conflicts of interest in this work.

\section{References}

1. Solem CA, Loftus EV, Tremaine WJ, Sandborn WJ. Venous thromboembolism in inflammatory bowel disease. Am J Gastroenterol. 2004;99(1):97-101.

2. Irving PM, Pasi KJ, Rampton DS. Thrombosis and inflammatory bowel disease. Clin Gastroenterol Hepatol. 2005;3(7):617-628.

3. Collins CE, Rampton DS. Platelets in inflammatory bowel diseasepathogenetic role and therapeutic implications. Aliment Pharmacol Ther. 1997;11(2):237-247.

4. Bernstein CN, Blanchard JF, Houston DS, Wajda A. The incidence of deep venous thrombosis and pulmonary embolism among patients with inflammatory bowel disease: a population-based cohort study. Thromb Haemost. 2001;85(3):430-434.

5. Talbot RW, Heppell J, Dozois RR, Beart RW Jr. Vascular complications of inflammatory bowel disease. Mayo Clin Proc. 1986;61(2): $140-145$

6. Nguyen GC, Sam J. Rising prevalence of venous thromboembolism and its impact on mortality among hospitalized inflammatory bowel disease patients. Am J Gastroenterol. 2008;103(9):2281-2283.

7. Al-Mofarreh MA, Al Mofleh IA, Al-Teimi IN, Al-Jebreen AM. Crohn's disease in a Saudi outpatient population: is it still rare? Saudi J Gastroenterol. 2009;15(2):111-116.

8. Al-Ghamdi AS, Al-Mofleh IA, Al-Rashed RS, et al. Epidemiology and outcome of Crohn's disease in a teaching hospital in Riyadh. World $J$ Gastroenterol. 2004;10(9):1341-1344. 
9. Isbister WH, Hubler M. Inflammatory bowel disease in Saudi Arabia: presentation and initial management. J Gastroenterol Hepatol. 1998;13(11):1119-1124.

10. Khan AB, Bhat N, Hassan A, Al Saied G. Aortic thrombosis complicating Crohn disease: an unusual complication. Can J Surg. 2009;52: E182-E184.

11. Al Tahan A, Mageed S, Al Momen A, Zaidan R, Daif A, Al Tahan F. Cerebral venous thrombosis as a complication of ulcerative colitis associated with protein-S deficiency: case report and review of the literature. Saudi J Gastroenterol. 1998;4(1):34-37.

12. Crohn B, Ginzburg L, Oppenheimer G. Regional enteritis: a pathological and clinical entity. JAMA. 1932;99:1323.

13. Mokhtar A, Khan MA. Crohn's disease in Saudi Arabia. Saudi Med J. 1982;3:207-208.
14. Quera R, Shanahan F. Thromboembolism: an important manifestation of inflammatory bowel disease. Am J Gastroenterol. 2004;99(10):1971-1973.

15. Danese S, Papa A, Saibeni S, Repici A, Malesci A, Vecchi M. Inflammation and coagulation in inflammatory bowel disease: the clot thickens. Am J Gastroenterol. 2007;102(1):174-186.

16. Miehsler W, Reinisch W, Valic E, et al. Is inflammatory bowel disease an independent and disease specific risk factor for thromboembolism? Gut. 2004;53(4):542-548.

17. di Fabrio F, Obrand D, Satin R, Gordon PH. Intra-abdominal venous and arterial thromboembolism in inflammatory bowel disease. Dis Colon Rectum. 2009;52(2):336-342.

\section{Publish your work in this journal}

Clinical and Experimental Gastroenterology is an international, peerreviewed, open access journal, publishing all aspects of gastroenterology in the clinic and laboratory, including: Pathology, pathophysiology of gastrointestinal disease; Investigation and treatment of gastointes tinal disease; Pharmacology of drugs used in the alimentary tract;
Immunology/genetics/genomics related to gastrointestinal disease. This journal is indexed on CAS. The manuscript management system is completely online and includes a very quick and fair peer-review system. Visit http://www.dovepress.com/testimonials.php to read real quotes from published authors.

Submit your manuscript here: http://www.dovepress.com/clinical-and-experimental-gastroenterology-journal 